\title{
RIGHTS-BASED EDUCATION IN NEPAL: EXISTING STATUS AND CHALLENGES
}

Damodar Jnawali, PhD

Professor

Department of Geography Education

Tirbhuwan University , Kirtipur

\begin{abstract}
This paper is an attempt to deal with the issues and challenges of rights-based education in Nepal with specific reference to minority and disadvantaged group children at school level. Data and information are from three year formative research activities completed under the commission of CERID, TU, Nepal. Discourses of various stakeholders were solicited in order to elicit information. Students' interactions, class observations, focus group discussions with people in local communities and district level officials, and district as well as national level workshops were conducted in order to elicit information for the study. The findings of the study indicate that the provisions for rights-based education are still inefficient in order to achieve the EFA goals. In spite of the attempts made by community, government, NGOs and INGOs, there are many challenges to provide rights-based education to those who are socially excluded.
\end{abstract}

Key words: Education for all, rights-based education, internally displaced children, disadvantaged groups, social exclusion.

\section{Context}

Education for All has become a major concern of various institutions, including governments, international agencies, donors, NGOs and civil society, but the prime responsibility for achieving these goals lies with government. In Nepal, the government has made serious efforts over the years to improve access to education and to create an enabling environment for quality education. However, government s upport alone is inadequate for achieving the school educational goals, particularly in the case of the children of socially excluded groups.

Low participation, low internal efficiency, high school dropout rates and low level of continuation in education are the consequences of inadequate access, poor school management systems and weak parent-teacher relations are among the multifaceted problems of school education. The major causes of low internal efficiency may be low achievement, high repetition and high dropout rates among primary school students, especially among disadvantaged groups. The present study is an attempt to explore the rights to education of disadvantaged children. Many efforts have been directed at improving access to education in our country; but not all of these efforts have been couched within the framework of a 'rights-based education'.
The 'rights-based approach to education' is a conceptual, analytical and methodological framework for identifying, planning, implementing and monitoring development activities based on international human rights standards. Nepal has made a commitment to achieve the Education for All goals as well as the Millennium Development Goals. The Convention on the Rights of the Child places responsibility on governments to ensure that all children have access to primary education. Nepal is attempting to achieve the Millennium Development Goals. These instruments mean that Nepal is committed to ensuring that by 2015, all children-particularly girls, children in difficult circumstances and those belonging to ethnic minorities - have access to complete, free and compulsory primary education of good quality.

\section{Methods and Materials}

The paper is based on information available from field survey, questionnaires, focus group discussion and observation were used for data collection. The respondents were student, their parents, teachers/head-teachers, DEOs and DOE officials.

The districts, representing three ecological zones and the Kathmandu Valley, were sampled for 
survey. Five disadvantaged groups, namely Chepang, Mushahar, Tamang, Tharu, and children from the slum areas and the Teresa Academy run by Maiti Nepal in Kathmandu were selected for data collection among disadvantaged groups. Students' focus group discussions, FGDs with community people, interviews with teachers and head-teachers and affiliations as reported by internally displaced persons (IDPs). All these causes were governed by political affiliation.

The major learning problems of IDCs were associated with a lack of materials, like pens, pencils, books, school bag and uniform. Inadequate teachers and lack of sufficient rooms

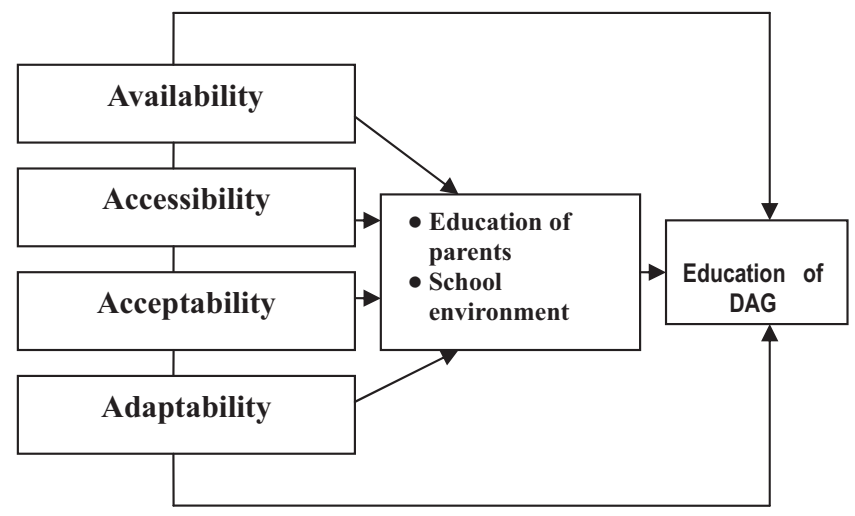

Figure 1

interviews with parents/guardians were conducted in each community in order to collect data. Some unique cases are also presented in the boxes.

Tomasevski's 4 A approach (Tomasevski 2004) works as a legal framework for rights-based education. In our case, it can be adopted as follows:

The figure indicates a relationship of education of disadvantaged children with many variables. Education of parents and school environment work here as intermediate variables. Availability, accessibility, acceptability and adaptability affect education of disadvantaged children through parents' education and school environment. They also directly affect education of DAG children.

\section{Major Outcomes and Implications}

There are a number of factors working as barriers to education for disadvantaged children. The study on the education of internally displaced children identified many barriers like threaten to kill, physical punishment, destruction of property, abduction of family members, murder of family members, looting and political and physical facilities were the major barriers faced by the IDCs in the schools surveyed.

Some of the children were found to be humiliated and dominated by their friends. The teachers and head-teachers reported that insufficient rooms and furniture, deteriorating student/ teacher ratios, difficulties in managing physical facilities, lack of safe drinking water and toilet facilities, lack of teachers, lack of time in checking homework regularly were the major aspects affected by the IDCs. These problems should be solved to meet the needs of the IDCs. The major psychological problems of the IDCs were associated with the events of looting their houses by insurgents, beating of parents, forcing to leave homes, and the destruction of their residences. A memory was created about such painful events that disturbed learning performance of the IDCs in the study area.

The major institutions providing support were DOCFA, Red Cross, SAFE Nepal and BASE. They supported IDCs for school uniform, books and bags, copies, and sometimes provided cash amount. However, these supports were not regular and sufficient for disadvantaged children. The schools were found to have a 


\section{Case 1: A Healthworker supporting IDP families at Kirannala, Banke}

An IDP Camp was located at Kirannala, Banke. A young person was supporting the IDP families at this camp. He was Manjan Shahi, a man of courage, commitment and dedication. He was also a displaced due to the effect of insurgency. Shahi, a moderate person of 25, was taking care of patients at the camp. He passed the SLC and later on he got training as a CMA. He was utilizing his knowledge and skills in treating sick people of the camp.

Manjan Shahi was not worried about permanent job. He was working with the IDPs and shared pathetic life styles of the IDPs. He stated, "We, the displaced people are always dominated and treated differently by other people in the community."

He further added, "The conditions of the IDPs are very miserable. Many families are looted and the houses are destroyed as well as burnt. However, they are not in a good mood to return to their area of origin. Some NGOs and INGOs helped the people at the camp but this support is not regular."

Thanks to the Himalayan Foundation, the only one organization which is regularly providing medicine for the camp people. The Nepal Government was not paying attention to the people of the IDP camp.

Shahi said, "The government is not taking care of these people." If the government provided at least one Katthha land, the inhabitants of that camp could produce vegetables in order to support their livelihood. He expects political stability and restoration of peace on behalf of the government and insurgents as well.

Source: Jnawali et al., 2006.

contact with DOCFA for school dress, bag, stationary, development fees, and exam fees for boys and girls. An attempt was also made to involve them in school activities and discussion with parents was made to improve the educational status of the IDCs. However, their expectations were not fulfilled. The specific impact of programmes available from NGOs and INGOs included: creation of confidence among displaced children, motivation in learning and regular attendance in the schools, psychological relief and opportunities to make adjustment in new areas.

The IDCs in the study area reported that availability of good dress, bag to carry book, copy, free education, financial support by organizations, good school environment and scholarship from schools could be the remedial measures for bringing improvement in their existing conditions.

There was a need of performing roles and responsibilities on behalf of the government and various organizations/institutions and groups of people with specific reference to identification of criteria for internally displaced children, generation of actual and reliable data on IDCs, provision of special free education system to the children, safe environment in order to make teaching/learning effective, access of education to all level of people, provision of special education, occupation oriented educational programme, provision of hostel and special provision of programmes for IDCs.

School management committees were in need of creating good environment to make displaced children assimilate in the situation, encourage them and make them aware about this, encourage and support the IDCs' study, create an opportunity of free education and school material such as dress and stationery, interaction with parents, creation of a school fund for displaced children, establish IDC scholarship and search for support to other non governmental organization. It was also suggested that the Parent Teacher Association (PTA ) has to collect resources and provide direct support to initiate programmes focusing on displaced children, control over programmes that were not suitable to the schools, free education and reformation at school according to the changing needs of the IDCs.

Regarding the rights-based education, most of the respondents were found not to have conceptual clarity about rights-based education. 


\section{Case 2: Major obstacle for Nurpu's school education}

Nurpu Ghale aged 14 lives at Thade, Rasuwa in a Himalayan district of Nepal. He lives in a family of 8 members. He can simply read and write. Nurpu's mother passed away when he was very small. In the absence of his mother, he had to support household activities. He was interested to go to school and wants to study up to SLC but he is not getting that opportunity. Now he spends time by working in agricultural land.

Nurpu completed grade 5 at Thade. Since the school for upper grade is located at a distance of 2 hours on foot, he is compelled to leave school. Thus, geographical distance and poor economic status are working as barriers to his education. In spite of keen interest in study, Nurpu is not able to attend school. He is expecting support from community, VDC and the government institutions.

Source: Jnawali et al., 2008.

The studies found inadequate learning conditions in most of the schools sampled. There was a lack of curriculum materials, teaching as well as reading materials like textbooks, pencils and pens. These should be managed by the school concerned. Instructional materials were not properly managed. Classroom delivery was not found to be student oriented. The process of textbook memorization was followed.

The students at grade 1 in Rasuwa were found not to understand teaching through the Nepali medium because the majority of them were from the Tamang community whereas the teachers were from other communities and were not able to communicate subject matter effectively in the Tamang language. In this context, the teaching at grades 1 and 2 should be made through mother tongue.

There was no proper management of monitoring and supervision in the schools surveyed. The school teachers and supervisors reported that the criteria of supervision and providing remuneration were not fixed by the government. In the same way, the Managing Committee was not given the responsibility of supervision. On the other hand, the school supervisors were found not be regular in performing their responsibility of monitoring and supervision of the schools assigned. Regarding health related issues, the first aid materials were not available in some of the schools. Even if available, they were inadequate.

Geographical distance/remoteness was found to be a barrier to education for disadvantaged children. In the area of Mushahar community in
Nawalparasi and the Tharu community in Kailali, the schools were located at a distance of 10 minutes. The case of Dhading and Rasuwa was different because in Rasuwa, the children had to move a distance of 45 minutes and even 2 hours in some cases.

The study indicates that lack of awareness among parents generally is working as the major barrier to educating children. Parents were not aware about the importance of education. So they were not giving proper environment to their children at home. Parents / guardians and other stakeholders were found to prioritize income generation over the rights to education for children. The provisions for ensuring learners equitable access to formal schooling and alternative modes of learning including Non Formal Education (NFE) were found inadequate.

Poverty was found to be a critical problem to disturb school education of DAG children. In this context, each of the members in the family had to help in order to sustain school attendance. Engagement of children in household chores was one of the barriers to education. The children had to support parents in cooking food, collecting wood, bringing water, cutting grass, grazing cattle, ploughing field and taking care of their siblings.

Early age at marriage was one of the major barriers to education among DAG girls. Muslims preferred to send their daughters to the local madrasa (Quranic school). Due to their poor financial condition, the majority of parents could not send their children to the public schools. The major reasons for girls' high dropout rate 


\section{Case 3: Early marriage as a barrier to education for Tharu girl}

Manju Rana, a girl aged 14 is a student of grade 8 at Behada Baba Secondary School, Ghasita in Kailali. There are five members in her family. All of the children are going to school. Manju has one brother and one sister. They are studying at grades 7 and 4 respectively. Manju's father is a farmer holding 2 bighas of agricultural land. The family has kept two bullocks, five goats and some chickens. The economy is at subsistence level.

Asked about the motivation for education, Manju replied that it was due to her own interest and commitment. Parents did not want to continue her education. They are rather prepared for her marriage at earlier age. Manju reacted, "My parents had decided to get me married when I completed grade 7. I did not accept their proposal and joined grade 8. I would like to continue my study. However, I am afraid of parents' decision about marriage. There is still gender discrimination among the Rana Tharus."

Manju further added, "The traditional values have not been changed in our society. The daughters are neglected because they have to leave parents after marriage. The parents think that they will not get benefit by nurturing their daughters." The case of Manju is an evidence to prove that the Tharu society has not yet changed. The people in that community have no consciousness about the benefit of education. Manju looked frustrated and said that people talked of male and female as two wheels of a chariot but it was not exercised in reality. Manju further added that there was a need of revolt against traditional system of educating children with a feeling of discrimination.

The researcher also interviewed Mr. Khem Raj Kushmi, a teacher of Rastriya Lower Secondary School, Urmi to check this case. Mr. Kushmi replied in positive. He said that about 25\% of the Tharu families wanted to manage daughters' marriage at the age of 14 to 15 years. In the same way, approximately $50 \%$ of the boys were found to be married by 20. Asked about the earlier marriage of girls, Mr. Kushmi added that the girls are matured early. If they were well educated, it was difficult to get qualified bridegroom. So, the parents want to get them married early.

Another factor was that the girls even studying at grade 5 started to fall in love with boys and leave school for engagement with them. Mr. Kushmi presented an example of girl studying at grade 5. He said that the girl herself married a boy when she was only 14. This is the evidence to prove that parents are compelled to get daughters married at earlier age. The other two examples were presented by Shakuntala and Laxmi of Geta - 7, Srilanka. Shakuntala was married twice before the age of 18 and Laxmi also did so. The evidence was presented by Bhalamansa, the Head of the village/community.

Source: Jnawali et al., 2008.

were found as: i) failure in class, ii) social norms and iii) physical maturity. Gender equality will not only empower women to overcome poverty, but will also assist their children, families, communities and countries as well. When seen in this light, gender equality is not only morally right - it is pivotal to human progress (UNICEF, 2007).

The programmes organized for disadvantaged children to ensure rights to education were not addressing majority of these children.

\section{Policy Recommendations}

Based on the findings of data available from field survey, the following recommendations are made:

- There is a strong need of making people aware about rights-based education concepts through media and door to door visit, street, and stage drama and wall paint.

- Some criteria/indicators should be developed in order to identify the 
disadvantaged children. Verification measures may include a recommendation letter from a local elected body.

- In order to avoid duplication, support from different sources should be pooled and distributed to disadvantaged students through a single system.

- The GOs (DEO) have to play leading and coordinating role; local bodies like DDC, VDC, Municipality have to play supportive role; I/NGO, CBOs and other IDP support organizations should play supportive role; journalist, civil society and professional organizations have to play supportive role and the school community (HT, Teachers, SMC, PTA) has to perform the role of management and support.

- The amount of support needs to be increased to the optimum level required by the students. Support should be provided only to real disadvantaged children.

- The DOE should support and take initiation in classroom construction and furniture distribution program under EFA. In the same way, the number of teachers should be increased.

- The teachers from low STR to high STR district or school should be transfered .

- Alternative schemes like per capita funding to the high STR schools should be provided.

- In school, there should be a separate toilet system for girls.

- Curriculum and curriculum materials by CDC in cooperation with DOE should be distributed in time and orianted to teachers.

\section{Conclusion}

The present paper was an attempt to examine rights-based education in Nepal with reference to its existing status and challenges. It is obvious that the amount of student support needs to be increased to the optimum level required by them. New and potential internal and external donors should be investigated and coordinated.

There is a need of a psychosocial counseling centre in schools where the numbers of IDP students are high. This program should be implemented through training of teachers.

There is a strong need of making respondents aware about rights-based education through media, door to door visits, street and stage drama and wall posters. Teachers should be provided training on rights-based education. There is a need of resource mobilization at local level for developing infrastructure. There is also a need to increase the non-salary recurrent expenditure including the spending on safety measures. A safe environment should be created in all school. School health programmes, including a health clinic have to be organized. The teachers have to be trained in order to create a genuinely childfriendly environment in the schools and classroom. One child-friendly school in each resource centre should be developed and this model should be replicated in other schools. Counseling the IDCs and children of backward and deprived communities is also essential.

There is also a need for raising awareness, initiating parental education and conducting capacity building programs. Language training program for teachers in consultation with parents is essential. Learning materials of the children's respective languages should be prepared and managed. The text books should be produced and distributed in time and children and their parents have to be ensured about their availability. The government and local bodies have to develop policy to award scholarship for card holders based on poverty indicators. The amount of scholarship should be raised to the needy students and tracked the scholarship amount from MOES to the targeted children. 
A strong monitoring mechanism at all levels has to be developed. There is a need of providing midday meal for all students at primary level and the parents have to be encouraged to share money/materials for it. Education acts and regulation have to be revised in line with student's representation in the SMC. Child clubs and child parliaments at the school and local levels should be developed. The children should be involved to develop their own code of conduct and find out ways to support out of school children and their parents with incentive schemes. Provision of alternative schooling for children not enrolled in schools has to be managed. Enrolment and awareness campaign have to be organized. Collaboration with various organizations is required for developing skills and income generating programmes.

There is a need for defining rights of all children, with particular focus on marginalized children, to education and formulate policies regarding child rights with specific reference to ECD and primary level education.

There is a need to develop tasks and responsibilities in consultation with the relevant agencies, institutions and persons; to develop a regulatory framework in consultation with the line agencies; and to develop a code of conduct for the reinforcement of children's rights to education at all levels.

The government should provide resources to schools through multiple ways such as regular budget, one time grant, matching fund, per capita funding and reward formulate a policy of transitional language program for students who could not understand, speak Nepali language in the classroom, and support programmes to implement mother tongue courses in primary schools as well as in higher studies wherever necessary. Schools should manage instruction through mother tongues in all primary schools. Government should facilitate optional courses in mother tongues in all schools based on the interests of the community and students.

Educational administration should be given to the capable person and a good relation should be established between DEO and the school management committee. The government should provide adequate support to students through scholarships, grants, free textbooks, exercise books, bags and Tiffin. The curriculum and educational material should be developed according to the needs and preferences of the local people. 


\section{Acknowledgments}

The author would like to extend thanks to the CERID, TU for providing opportunity to carry out research on rights-based education. Similarly, he extends thanks to Prof. Kristine Tornes and Mr. Halfdan Farstad, for sharing ideas during the process of preparing this paper.

\section{References}

CERID (2005). Fact Sheet and Issue 9 June 2005, Kathmandu: Research Centre for Educational Development and Innovation.

CEFA (2003). Gender Responsive Non-Formal Education in Nepal: A Case Study, Kathmandu. Centre for Education for All Nepal/UNESCO, Kathmandu Series of Monographs and Working Paper 5.

Chitrakar, Roshan, et. al. (2007). "Longitudinal Study on System Indicators: Cohort and Trend Analysis". Research Report Submitted to the Research Centre for Educational Innovation and Development.

DOE (2005). Flash Report 1 2062. Sanothimi: Department of Education.

DOE (2005/2006). Flash Report 11 2062. Sanothimi: Department of Education.

DFID (2005). "Reducing Poverty by Tackling Social Exclusion." A DFID Policy Paper Published by the Department for International Development.

Gurung, Harka (2006). "Social Inclusion and Nation Building in Nepal." Lalitpur: Social Inclusion Research Fund Secretariat: 4-6.

Jnawali, Damodar et. al. (2006). CERID, “Education for Internally Displaced Children: Provision and Challenges." Report Submitted to CERID, Tribhuvan University.

Jnawali, Damodar et. al. (2007). CERID, "Rights-based Education and Structural Reforms in Basic and Primary Education: a Study on Institutional Needs and Community Readiness" Report Submitted to CERID, Tribhuvan University.

Jnawali, Damodar et. al. (2008). CERID, "Education of Disadvantaged Children in Nepal: a Study on Existing Status and Challenges." Report Submitted to CERID, Tribhuvan University.

Luitel, Samira, et. al. (1997). "Social Assessment of Educationally Disadvantaged Groups." Report Submitted to CERID, Tribhuvan University.

Nepal Government (2007). Nepalko Antarim Samvidhan 2063. Kathmandu: Chandeswari Prakashan Pvt. Ltd.

Phuyal, Narendra et. al. (2005). "Access of Disadvantaged Children to Education." Report Submitted to CERID, Tribhuvan University.

Sommers, Marc (2002). "Children, Education and War: Reaching Education for All (EFA) Objectives in Countries Affected by Conflict." CPR Working Paper 1 accessed on Dec 12008.

Tomasevski, K. (2004). Manual on Rights-based Education. Bangkok: UNESCO Asia and Pacific Regional Bureau for Education.

UNESCO (2005). Guidelines for Inclusion: Ensuring Access to Education for All. Paris: UNESCO.

UNICEF (2007). The State of the World's Children 2007. New York: United Nations Children's Fund. 